\title{
A PANDEMIA DE COVID-19 E A POSSIBILIDADE DE REFORMULAÇÃO DO CONHECIMENTO CIENTÍFICO E GEOGRÁFICO
}

\author{
Karina Eugenia Fioravante ${ }^{1}$ \\ Universidade Estadual de Ponta Grossa \\ karinafrr@gmail.com
}

RESUMO:

Nos dias atuais, inúmeras exigências e desafios estão sendo colocados às ciências. Objetivo discutir nesse ensaio como nós, cientistas e geógrafos, estamos respondendo as incertezas e desafios que surgem, bem como, a possibilidade que temos nesse momento de rever antigos percursos, repensar nosso fazer geográfico para produção de um conhecimento verdadeiramente relevante, atual e pontente.

Palavras-chave: Pandemia; Covid-19; Conhecimento Científico-Geográfico.

\section{COVID-19 E A REFORMULAÇÃO DO CONHECIMENTO CIENTIFICO-GEOGRÁFICO}

Para os cientistas sociais que se mantêm atentos aos acontecimentos cotidianos, a declaração de Boris Johnson de que devia sua vida ao sistema de saúde pública britânico, o National Health Service (NHS) é, ao mínimo, extremamente interessante. O primeiro ministro e líder do partido conservador inglês sempre se posicionou em defesa feroz de interesses neoliberais os quais, por natureza, tensionam fortemente todo e qualquer aparato público. $\mathrm{O}$ relato de Johnson ${ }^{2}$ pode incitar os mais ferrenhos a adotar uma postura debochada, apontando a incompatibilidade existente entre seu discurso e sua vida cotidiana, afinal, foram os serviços do NHS que garantiram seu bem-estar atual, e não os esforços da iniciativa privada por ele tão advogados. Estariam essas pessoas equivocadas? Não, nem um pouco. A ironia da situação também pode ensejar algumas acaloradas reflexões escritas por mãos sedentas em explicar as mazelas e infinitas coerções que um sistema capitalista perverso vem instaurando em nosso meio social. Para a Geografia e seu conjunto de matrizes explicativas, o depoimento do

\footnotetext{
${ }^{1}$ Professora substituta na Universidade Estadual de Ponta Grossa.

${ }^{2} \mathrm{O}$ primeiro-ministro britânico se pronunciou na mídia para agradecer o tratamento que recebeu durante sua internação devido ao contágio pelo novo coronavírus.
} 
primeiro ministro é um prato cheio de possibilidades para que dedos sejam apontados e poucas soluções sejam oferecidas. Entretanto, a fala de Johnson, que em última análise demonstra apenas sua gratidão ao corpo de profissionais que foram responsáveis por seu atendimento hospitalar, me levou a ponderar sobre nossa capacidade de produzir respostas, direcionar ações e apontar soluções a partir da produção de um tipo de conhecimento específico, o científico e, em especial, o científico-geográfico.

Nesse momento, em que a vulnerabilidade das comunidades humanas está mais explícita do que possivelmente jamais esteve, o conhecimento científico tem sido utilizado como ancoragem, como porto seguro e tornou-se o responsável último pela produção de soluções, estas tão almejadas e necessárias. A valorização das ciências está em pleno processo de ebulição e, consequentemente, práticas adotadas pela comunidade científica tornam-se cada vez mais visíveis. O que jamais podemos obliterar é que a ciência é produzida por seres sociais amparados por um complexo, e por vezes conflitante, sistema de referências, conceitos, categorias, métodos e caminhos de análise. Tais ferramentas permitem a construção de uma visão particular de conhecimento que objetiva, por certo, alcançar explicações e oferecer respostas aos desafios que a vivência socioespacial nos coloca cotidianamente.

Sendo assim, o questionamento acerca das potencialidades de nossas maneiras de produzir conhecimento não deve ser negligenciado, bem como, a posicionalidade que os próprios pesquisadores adotam em momentos de crise. Tais posturas refletem diretamente em nossa capacidade de assegurar e prover resultados que são essenciais para a superação de situações de instabilidade e provações. Esse processo de escrutínio do conhecimento científico não sugere, de maneira alguma, uma tentativa velada de desacreditá-lo ou depreciálo. Longe disso. Demonstra uma vontade inabalável de fortalecê-lo, garantindo que discursos, relatos e resultados tornem-se os mais blindados possíveis teoricamente e, também, na sua práxis. Tal tarefa pode ser inalcançável mas não devemos nos curvar perante ela.

Morin (2010, p.67) aponta que a ciência é “(...) intrínseca, histórica, sociológica e eticamente, complexa." É sobre tamanha complexidade que nós, cientistas, devemos nos concentrar, objetivando a criação de esquemas explicativos que sejam capazes de dar conta do real sem jamais deixar de considerar a heterogeneidade de questões que a própria prática científica escancara. Na medida em que a ciência é, indubitavelmente, fruto de seu contexto 
histórico, social, cultural, espacial e político, suas práticas devem responder as necessidades trazidas por tais demandas. Como nós, guardiões e produtores do conhecimento geográfico, estamos respondendo a elas? A humanidade tem colocado e nos desafiado com uma série de questões que, até o presente momento, parecem ou insolucionáveis ou de difícil apreensão. Qual o papel da Geografia e dos geógrafos? Essa pergunta audaciosa me direciona para uma multiplicidade quase que inesgotável de possibilidades e tais possibilidades estão diretamente correlacionadas com a própria evolução de nossa ciência ao longo do tempo e do espaço. Não objetivo aqui estender-me longamente nas diversas definições que nossa ciência já possuiu. É certo que as maneiras de compreendê-la e de colocá-la à serviço da sociedade, que as formas de construirmos geografia alterou-se consideravelmente ao longo dos anos.

Os vários subcampos investigativos, cada um com suas especificidades e fragilidades, com seus olhares e percursos, todos são capazes de, nesse momento, garantir que algum tipo de informação proveniente da Geografia seja produzida. A partir de pontos de vistas, que incluem as mais numerosas perspectivas e elementos, os geógrafos podem abraçar a temática da pandemia que vivenciamos e, a partir dela, apresentar reflexões. Meu questionamento sempre se direciona, nesse sentido, para a relevância e utilidade de seguirmos alguns caminhos que, ao mínimo, já encontram-se consolidados no contexto científico da disciplina.

Sendo assim, de maneira extremamente superficial, posso apontar que os geógrafos irão concentrar esforços analíticos para dar sua contribuição e tentar responder às indagações sociais que nos colocam. Investigarão as especificidades culturais, os hábitos e vivências de populações e como estas serão afetadas por um desequilíbrio social tão forte. Suas reflexões resultarão em longos inventários que apontarão particularidades, modos de compreender a vida e a geografia de tudo isso. Também não faltarão trabalhos que garantam visibilidade à vulnerabilidade exacerbada de determinadas parcelas da população. Diários de campos e compilações de relatos empíricos possivelmente serão combinados às nossas estimadas técnicas cartográficas e grandes mapeamentos serão disponibilizados para todos os interessados. Os marxistas dificilmente resistirão a tentação de analisar as consequências de tal crise de saúde pública a partir das contradições inerentes do capital. Irão prever crises, graves e impactantes. Irão apontar que nossos espaços, que nossas cidades, tão segregadas, necessitam de reformas e reajustes urbanos. Serão, certamente, seguidos pelos geógrafos 
urbanos e tal discurso ganhará força e estatuto de verdade quase que instantaneamente. A chamada Geografia da Saúde possivelmente será coroada e passará a ser temática discutida em um diálogo com subcampos consolidados e de grande respeitabilidade.

Para os que acreditam na dicotomização da disciplina, a Geografia Física não ficará devendo nada. As questões da poluição, das alterações climáticas e de vulnerabilidades ambientais serão apontadas para reforçar o discurso de que a natureza e as problematizações referentes a ela devem ser repensadas. Nossos conceitos-chaves, espaço, paisagem, território, lugar, região e escala não descansarão. Deverão demonstrar seu potencial dentro de nossos sistemas consolidados de ideias, de formas de compreender o mundo. Também não haverá pausa para nossas proposições metodológicas e posições epistemológicas de longa data laureadas e quase que nunca questionadas.

A Geografia irá oferecer reflexões e elas serão múltiplas e, principalmente, previsíveis dentro de nosso escopo investigativo e de nossa maneira tão característica de análise. A compreensão de que construímos nossos acertos e nossas certezas tendo como base o erro e a dúvida é, nesse cenário, essencial. A pandemia global que hoje vivenciamos traz, dentre suas múltiplas incertezas, a assertiva incontestável de que o conhecimento científico precisa evoluir para acompanhar as demandas sociais. Essa evolução implica, não obstante, a manutenção de um olhar aberto para possibilidades que até então permanecem não exploradas e se correlacionam diretamente com a reconstrução de teorias e métodos.

Investigações de especificidades culturais e populacionais, de impactos urbanos e econômicos, da vulnerabilidade social e das problemáticas naturais são relevantes, mas serão suficientes? Serão verdadeiramente satisfatórios os exaustivos mapeamentos para o enfrentamento de uma condição sobre a qual temos muitas perguntas e quase nenhuma resposta? Será suficiente utilizar ideias santianas e afirmar que o colapso de algumas regiões ocorrerá devido a diferenciação da disseminação do meio técnico-científico-informacional sobre o território brasileiro? Ou apontar que o despreparo no enfrentamento se relaciona a diferenciações regionais de gestão e que a aplicação de políticas públicas deve ter em sua base o elemento espacial? Minha resposta a essas indagações é de que não, não serão suficientes. Apenas abandonando nossas certezas seremos capazes de sair vitoriosos. Se nos mantivermos a bordo de um barco que já há algum tempo vem apresentando fissuras, certamente muito em 
breve estaremos agarrados a um pequeno pedaço de madeira à deriva. A Geografia precisa dar um salto e tomar como prática comum a necessidade de continuamente se (re)pensar. Novos caminhos precisam ser construídos.

Grande parte da dificuldade de construirmos novas teorizações e metodologia está diretamente relacionada com nossa própria postura como cientistas. Latour (2012, p.201) aponta que um grande problema dos cientistas sociais é que "(...) alternam quase sempre entre a hybris - todos querem ser o Newton da ciência social ou o Lênin da mudança da sociedade - e o desespero. Desprezam-se por viver empilhando relatórios, histórias e estatísticas que ninguém lerá. Mas a escolha entre maestria completa e irrelevância absoluta é muito superficial." A hierarquia acadêmica, tão preciosa para alguns, bem como, a maestria quando alcançada, pode levar a criação de relações de poder que impossibilitam e/ou vetam tentativas de cientistas que buscam o ainda inexplorado. Não é incomum que vejamos a criação de guetos científicos que, ao se apropriarem de uma temática particular tendem a esgotá-la. Um cenário muito mais perverso ocorre quando alguns são capazes de controlar o discurso e o direcionamento que a própria ciência vivencia com relação a temáticas particulares. Para Santos (2018, p.61), “(...) a comunidade científica estratificou-se, as relações de poder entre cientistas tornaram-se mais autoritárias e desiguais". Tais relações de poder refletem-se, inclusive, na decisão do que é ou não importante ser investigado pelas disciplinas. A posicionalidade do pesquisador sempre é, nesse sentido, política. Se permanecem apegados ao velho, propondo problematizações que não passam de releituras frágeis e já visadas, pouco contribuem. Tal postura de 'masturbação científica e moral' (HARVEY, 2020) deve ser evitada, especialmente em um momento em que situações gravíssimas precisam ser enfrentadas.

Devemos submeter a um exame rigoroso nossa postura científica, nossas teorias e, também, nossa sociedade. Para Harvey (2020, p. 42), essa é a primeira abordagem para que tenhamos sucesso na construção de explicações que, de fato, sejam capazes de garantir uma melhoria na qualidade de vida da população. A construção consciente e atenta de um novo conjunto de conceitos, métodos, categorias e argumentos só virá a partir do momento em que sejamos capazes de mobilizar “(...) nossos poderes de reflexão para formular conceitos e 
categorias, teorias e argumentos, aplicando à tarefa de levar a cabo uma transformação social e humanizadora".

Pensar em termos do novo não implica o desprezo absoluto a tudo que antes foi concebido. O desafio está na construção de um corpus teórico capaz de responder aos fenômenos atuais e isso só será possível com a adoção de uma postura crítica e libertadora. É necessário que levemos em consideração outras epistemologias, outras formas de conceber sem que nos prendamos a abstrações idealistas ou ao pragmatismo ortodoxo. $\mathrm{O}$ risco de nos encontrarmos em um beco sem saída não é pequeno e deve nos servir de alerta. É preciso manter em mente que a mudança na maneira como concebemos o mundo, a sociedade e, claro, a Geografia não implica em um processo árduo de ruptura. Pode relevar, como aponta Santos (2018, p. 62), “(...) o retrato de uma família intelectual numerosa e instável, mas também criativa e fascinante, no momento de se despedir, com alguma dor, dos lugares conceituais, teóricos e epistemológicos, ancestrais e íntimos, mas não mais convincentes e secularizantes (...)”. Essa despedida deve visar, sempre, a busca por uma vida melhor, com melhores condições, maior justiça social, maior pluralidade de trajetórias e, principalmente, maior capacidade de dar respostas rápidas a problemas que venham a nos acometer. Reinventando-se, a Geografia tem muito a contribuir para tanto.

\section{REFERÊNCIAS BIBLIOGRÁFICAS}

HARVEY, D. Os sentidos do mundo. Textos essenciais. São Paulo: Boitempo, 2020.

LATOUR, B. Reagregando o social. Uma introdução à teoria do Ator-Rede. Salvador: EDUSC, 2011.

MORIN, E. Ciência com consciência. Rio de Janeiro: Bertrand Brasil, 2010.

SANTOS, B. de S. Um discurso sobre as ciências. São Paulo: Cortez, 2018. 